\title{
Turismo Pedagógico: ressignificando a aprendizagem
}

\section{Pedagogical Tourism: Resignifying Learning}

Rosiane de Morais, Luciana Paes de Andrade, Neiva Maria Robaldo Guedes

RESUMO: Ressignificar o método de aprendizagem é eminente no cenário educacional contemporâneo. Faz-se necessário a ligação da teoria com prática. O papel da escola vai além de repassar conhecimentos, cabe a ela também a formação de um cidadão crítico, participativo e atuante na sociedade. O Turismo Pedagógico como método inovador, dinâmico e interdisciplinar no processo de ensino aprendizagem, proporciona momentos de lazer e educação. Ele aproxima o aluno do meio, busca proporcionar uma experiência consolidadora de valores e transformadora de si, catalisadora de saberes. Explorar, identificar e criar possibilidades de aprendizagens significativas ao contexto local foi o principal objetivo deste trabalho. A participação dos alunos é intensa, quando os mesmos percebem a participação e domínio dos educadores sobre as atividades propostas. O processo de tomada de decisão e sensibilização só acontece quando se conhecem novas realidade, cultura, história e patrimônio.

PALAVRAS-CHAVE: Escola; Turismo Pedagógico; Educação Ambiental; Cidadania; Patrimônio Natural.

\begin{abstract}
Resigning the learning method is imminent in the contemporary educational setting. It is necessary to link theory with practice. The role of the school goes beyond passing on knowledge, it is also up to it to train a citizen who is critical, participatory and active in society. Pedagogical Tourism as an innovative, dynamic and interdisciplinary method in the process of teaching learning, provides moments of leisure and education. It brings the student in the middle, seeks to provide a consolidating experience of values and transforming itself, a catalyst for knowledge. Exploring, identifying and creating possibilities for meaningful learning in the local context was the main objective of this work. The participation of the students is intense, when they perceive the participation and mastery of the educators about the proposed activities. The process of decision-making and sensitization only happens when new reality, culture, history and heritage are known.
\end{abstract}

KEYWORDS: School; Pedagogical Tourism; Environmental Education; Citizenship; Natural Patrimony. 


\section{Introdução}

Propor atividades diversificadas, desafiadoras, que saiam da rotina da sala de aula é uma estratégia importante na construção do conhecimento. Reconhecer e valorizar a diversidade local, conectar o ser humano com o ambiente natural. Interligar os conhecimentos teóricos a prática, permite ao educando assumir seu papel de pesquisador e transformador da sua própria realidade.

O Turismo Pedagógico neste contexto mostra-se como uma prática inovadora, representa a oportunidade aos educandos explorarem e se conectarem com o ambiente, e aos educadores trabalharem de forma multidisciplinar e holística (GOMES, 2012).

Explorar o olhar da criança para fora do ambiente escolar, fomenta a construção de cidadãos participativos e conscientes. O turismo pedagógico representa a oportunidade de explorar a relação homem-espaço nas mais variadas perspectivas de análise do conhecimento humano (geográfico, físico, biológico, ecológico, social) de forma lúdica, multidisciplinar e interativa, trazendo a eminente possibilidade de preservação do patrimônio natural e cultural dos locais visitados (LOUZEIRO, 2019).

As aulas passeios, viagens com fins educativos, não são novidades por exemplo na Europa, mas no Brasil muitas escolas não conhecem a função do turismo educacional como metodologia diferenciada no processo de ensino-aprendizagem (BENI, 2002; GOMES et al, 2012). Para que esta ferramenta possua êxito, é necessário que esteja previsto no currículo escolar e que os educadores recebam formações e orientações sobre esta estratégia.

Com relação ao turismo pedagógico, especificamente, Rubim (2010) afirma que:

O Turismo Pedagógico é a modalidade que se adequa à proposta de aproximar teoria e prática por constituir-se em sua essência por viagens ou excursões organizadas de estudo do meio com finalidade de transportar 0 conhecimento teórico, aprendido em sala para a realidade, enquanto oportuniza momentos de socialização e descontração.

A mobilidade proporcionada pelo turismo põe em contato muitas pessoas, amplia e enriquece as maneiras de pensar e de atuar, expandindo o acervo cultural. Essa viagem através do turismo educacional proporciona diversas formas de obter um novo conhecimento, contribui para o desenvolvimento não só da escola, mas para que as atividades que ocorrem fora do ambiente escolar tenham qualidade, para que os alunos se sintam motivados a explorar o espaço de maneira adequada enriquecendo o próprio conhecimento (BENI, 1998).

O caminho metodológico percorrido para a realização deste trabalho iniciou-se com a formação dos alunos que integram o ensino fundamental anos finais da escola em estudo. Durante cinquenta horas de formação os 
alunos participaram da revitalização da Trilha já existente na escola, identificação das principais aves e espécies arbóreas da área da reserva, sendo o Bioma Cerrado o predominante. Explorar, identificar e criar possibilidades de aprendizagem significativa ao contexto local foi o principal objetivo deste trabalho. Dentre os objetivos específicos: Incentivar o protagonismo juvenil (aluno educa aluno), tornar a escola uma um local de visitação para outras escolas e valorizar a biodiversidade local.

\section{Proposta Pedagógica Integradora}

Os processos formativos, na perspectiva da formação integral, pressupõem a experiência concreta dos educandos, sujeitos históricos e socialmente produtores de cultura (SILVA, ROSSARI, GIARETA; 2017). O conhecimento exige o pensamento abrangente, holístico e interdisciplinar, para sermos capazes de compreender o local e projetarmos para outras esferas.

Conforme Morin (2004, p.89) torna-se necessário substituir um pensamento que isola e separa por um pensamento que distingue e une, um pensamento disjuntivo e redutor por um pensamento complexo, no sentido originário do termo complexus: o que é tecido junto. O principal desafio a ser superado na educação brasileira é o atraso do sistema educacional, no que tange a valorização do educador, as práticas pedagógicas e a sua formação.

Superar a mera reprodução é um grande desafio da prática pedagógica, que ainda suscita investimentos profundos na constituição de referenciais confiáveis. A ausência de vínculos entre teoria e prática dos conteúdos abordados também é preocupante.

$\mathrm{Na}$ visão inovadora, o aluno é reconhecido como sujeito e produtor do próprio conhecimento, com atitude dinâmica, participativa, crítica, questionadora, inventiva e autônoma no processo de aprendizagem, vivenciando a relação dialógica com o professor e seus colegas.

$\mathrm{Na}$ intersecção entre atividades pedagógicas voltadas para o desenvolvimento dos aspectos cognitivos, afetivos e sociais dos alunos com as atividades lúdicas $e$ de entretenimento próprio dos passeios e das viagens, reside o espaço do turismo pedagógico. É o espaço da aprendizagem feita com prazer, mas não é aquele prazer típico da alienação, é o prazer que é fruto da ampliação do conhecimento, do esclarecimento, da convivência e do lúdico (VINHA, 2005, p. 15).

A interdisciplinaridade como ação pedagógica contribui para a construção de sujeitos participativos, solidários, articulando o conhecimento a experiências práticas cotidianas do aluno. Apap et al. (2002), afirmam que a inexistência dessas ações pode ser um déficit para a formação da cidadania. 
A educação deve ser permanente, continuada, objetivando a transformação social, contribuindo na formação de um cidadão político, tornando-se imprescindível a adoção de novas pedagogias transformadoras. Neste contexto o Turismo Pedagógico corrobora com a busca de caminhos para promoção de uma ação educativa cidadã realmente comprometida com a garantia da boa educação e da validação do direito da cidadania social e política. Esta contribui na prática com as escolas, proporcionando uma interação entre o sujeito e o meio, através da vivência e a valorização do patrimônio material e imaterial (BONFIM, 2010; FETTER, 2017).

O turismo possui um grande potencial no equilíbrio e aproximação do homem com a natureza, contribui na proteção do meio ambiente, pode promover a redução da pobreza por meio de uma atividade sustentável de subsistência, compatível com o desenvolvimento sustentável.

\section{Turismo Pedagógico: estratégia para novas práticas pedagógicas}

O turismo Pedagógico é um dos segmentos do turismo, mas não está entre os segmentos de oferta turística priorizados pelo Ministério do Turismo (MTur). O turismo no contexto pedagógico, desenvolve a construção da consciência cidadã, através do contato com os patrimônios históricos, culturais, ambientais, na concepção dos interesses turísticos como indutor da economia e no papel de preservação e valorização desses patrimônios (SILVA, 2015).

O Turismo como estratégia metodológica de aprendizagem, proporciona o desenvolvimento cognitivo através do lúdico e do lazer. Experiências prazerosas são ofertadas, levando os alunos a compreender a complexidade e relações socioculturais e históricas que transformam a paisagem, proporcionando a conversão e reconversão do olhar nos envolvidos.

Os benefícios que um passeio ou uma viagem podem ter no processo de aprendizagem através do estudo do meio são inúmeros. De acordo com Balzan (1987, p.115) "desde que se pretenda de fato desenvolver plenamente a personalidade do educando, o estudo do meio passará a se constituir como uma atividade de excepcional importância na vida da escola".

A preocupação com o Meio Ambiente se dá pela pressão desenfreada de crescimento, seja econômica, social e/ou política, tendo homem como o agente de transformação do meio. Desde o início da humanidade a natureza já era explorada pelo homem na tentativa encontrar meios de sobrevivência e satisfazer suas necessidades. As ideias de o homem como o centro do universo corroboram com inúmeros problemas ambientais, como: perda e fragmentação de habitats, redução da biodiversidade, contaminação de corpos hídricos, compactação do solo, entre outros.

Diante deste cenário é imprescindível que a escola oferte momentos de diálogo, conhecimento e respeito pelos ambientes diversos, desprovidos de fantasias e alienações. A educação deve ser vista como um processo social, onde o indivíduo cria seus próprios valores. 
Conforme descrito por Silva (2015, p.30): "O turismo pedagógico ensina os estudantes transformarem o olhar de residentes locais para um olhar do turista, desenvolvem uma percepção histórica e cultural do lugar em uma postura de valorização". Com as práticas de turismo pedagógico é possível oportunizar aos alunos novos conhecimentos sobre diversas culturas, promovendo novas experiências que ampliam a visão cultural, ambiental e social.

O principal elo entre Turismo e a Educação estão relacionados à troca de conhecimentos e socialização entre as pessoas. Reconhecer a necessidade de novas práticas pedagógicas é fundamental no processo de aprendizagem, a construção de um sujeito social crítico, reflexivo e participativo, capaz de atuar intensamente na sociedade. $O$ turismo pedagógico se coloca como uma alternativa importante, capaz de contribuir com as escolas proporcionando uma interação entre o sujeito e o meio através das experiências de viagem, visitas e aula passeio.

Esta troca permite a produção de novos conhecimentos, maior capacidade de compreensão do assunto estudado, contribui na formação integral do ser humano. Impulsiona o processo de ensino-aprendizagem de matérias tradicionais do currículo escolar na inovação das aulas, quebra o paradigma existente em sala de aula, onde o professor fala e 0 aluno somente escuta.

\section{Metodologia}

Para Chizzotti (2008) o fazer pesquisa implica adotar princípios, fundamentos lógicos e epistemológicos que endossam a análise da realidade, cujo valor esclarecedor e universal define a epistemologia da pesquisa.

A Escola Municipal Agrícola Gov. Arnaldo Estevão de Figueiredo, localiza-se na zona rural de Campo Grande - MS. Atende alunos do $1^{\circ}$ ano do Ensino Fundamental ao 3ํano do Ensino Médio. É uma escola de tempo integral e oferta Ensino Médio Profissionalizante em Técnico Agropecuária, com currículo escolar diferenciado e adequada realidade do Campo.

Dos 110 hectares que compõe a área da escola, aproximadamente 33 hectares são de reserva (remanescentes do bioma Cerrado). Os alunos desde $01^{\circ}$ ano do ensino fundamental já têm a disciplina de Prática de Campo no Currículo, porém observa-se que com a progressão dos anos escolares poucas novidades são propostas como metodologia de ensino.

$\mathrm{Na}$ Reversa da unidade escolar encontra-se uma trilha onde pode-se explorar e observar diferentes elementos naturais. Durante as aulas no Laboratório de Ciências os alunos do $8^{\circ}$ ano e $9^{\circ}$ anos do ensino fundamental anos finais, realizam a visita, restruturação da trilha já existente, identificaram as principais aves e árvores da reserva. 


\section{Turismo Ecológico: Pedagógica Integradora}

Para elaborar a atividade pedagógica integrada, deve-se atentar e ressaltar a interdisciplinaridade. Superar o currículo fragmentado e desarticulado é o principal objetivo desta prática. Para isso é necessário que o professor desde a sua formação inicial e também continuada, busque novas aquisições de habilidades e de um novo jeito de ensinar (SANTOS, COLOMBO JÚNIOR, 2018).

A educação turística vem a somar no campo da interdisciplinaridade, a elaboração de atividades que incluam algum tipo de deslocamento do ambiente escolar necessita a formação de grupos/equipes multidisciplinares para o efetivo estudo do meio. Temas como: cidadania, alteridade, sociabilidade, cultura, educação ambiental e patrimonial geralmente são pautas nestes roteiros (OLIVEIRA, 2016; VINHA, 2005).

Ao saírem da sala de aula, os alunos têm a oportunidade de ampliarem seus conhecimentos, perceberem os conteúdos trabalhos na teoria, possibilita novas experiências, exercitam a cidadania e traz o movimento para a escola. No processo de ensino humano, a relação social e a intermediação do outro são de grande relevância.

Durante as visitas, aulas passeios e/ ou viagens é importante que o conhecimento seja orientado através de um roteiro previamente elaborado, com o intuito de direcionar o conteúdo para uma melhor absorção pelos alunos, pois a prática por si só não se sustenta, e, se mal elaborado, pode, ao invés de estimular o conhecimento, criar dúvidas sobre os assuntos abordados.

O caminho metodológico percorrido para o desenvolvimento da prática integradora, seguiu as etapas abaixo:

10 Etapa- Visita a reserva da unidade escolar afim de identificar os possíveis elementos naturais que poderiam ser explorados em sala de aula e nas aulas práticas no laboratório de ciências.

20 Etapa- Realização de passarinhadas no período matutino para identificar as principais aves da reserva (Figura 1). Limpeza e sinalização da trilha. Com o auxílio de estagiários do curso de Biologia da Universidade Federal de Mato Grosso do Sul, realizou se a coleta, identificação e preparo de exsicatas das árvores próximas a trilha (Figura 2).

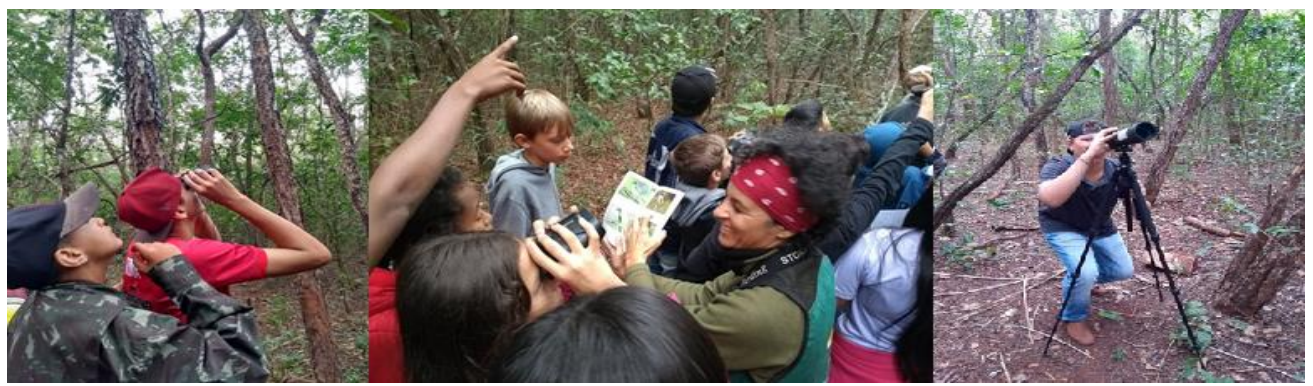

Figura 1: Alunos da Escola Municipal Agrícola Gov. Arnaldo Estevão de Figueiredo observando e registrando as espécies de aves presente na reversa da escola, Campo Grande - MS.

Figure 1: Students of the Arnaldo Estevão de Figueiredo Municipal Government School observing and registering as bird species present in the reverse of the school, in Campo Grande - MS. 


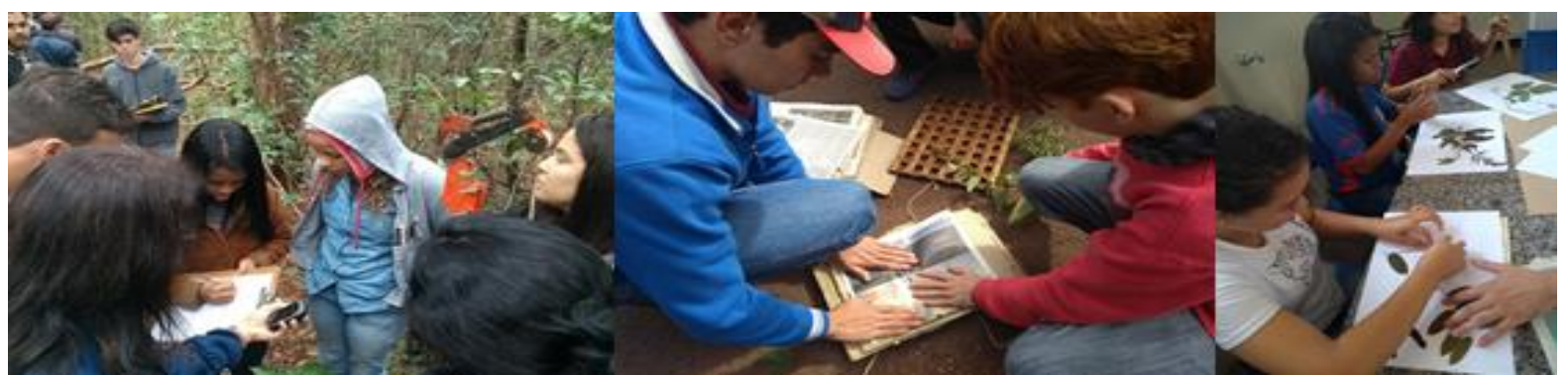

Figura 2: Coleta, prensagem, identificação e preparação das exsicatas das plantas encontradas próxima a trilha ecológica da reserva.

Figure 2: Collection, pressing, identification and preparation of the exsicatas of the plants found next to the ecological trail of the reserve.

30 Etapa- Após a identificação das principais aves confeccionou se uma placa educativa com a imagem de algumas aves e suas respectivas características (Figura 3). Para facilitar a identificação das árvores foi criado um QR-Code para cada espécie, com o aplicativo é possível acessar a uma plataforma que foi "alimentada" com informações diversas sobre a espécie. Um folder informativo foi elaborado pelos alunos, com informações sobre a escola, a reserva, o bioma Cerrado e as principais aves e plantas identificadas.

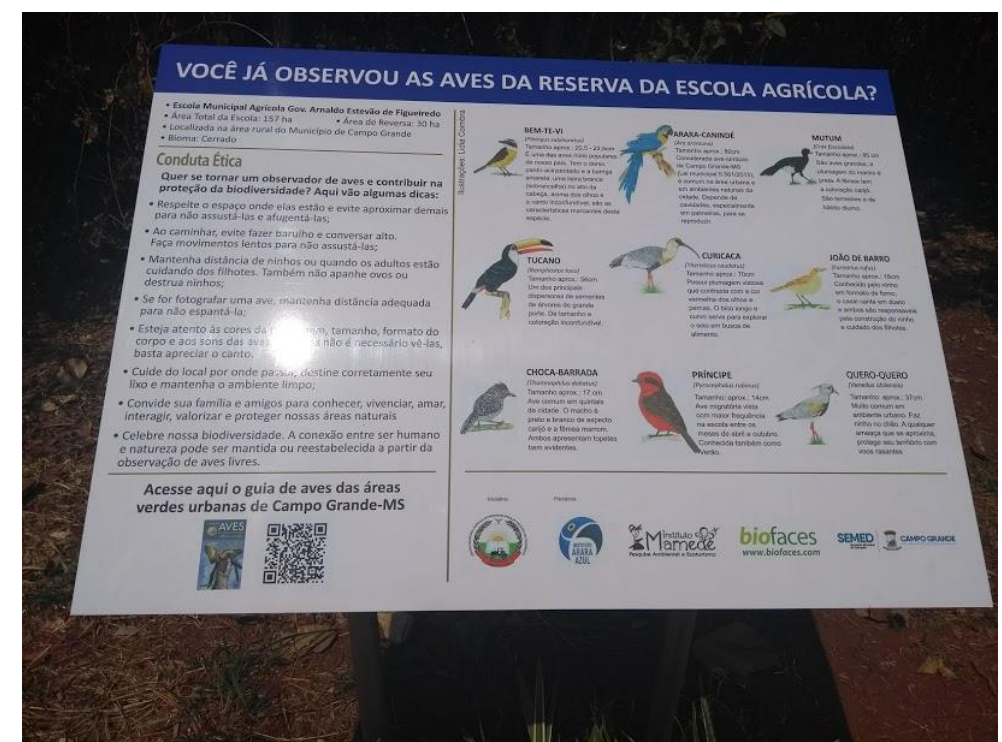

Figura 3: Placa com a identificação de algumas aves presentes na reversa da Escola Municipal Agrícola Gov. Arnaldo Estevão de Figueiredo.

Figure 3: Plate with the identification of some birds present in the reverse of the Municipal Agricultural School Gov. Arnaldo Estevão de Figueiredo.

4- Etapa: Por sugestão dos próprios alunos, os mesmos que participaram das etapas anteriores, atuaram como monitores para os demais alunos. Visitas monitoras foram realizadas na trilha. A visitação foi agendada antecipadamente e dividida em duas fases: a primeira é o curso de 650 metros de trilha e a segunda etapa a atividade de intervenção ambiental (Figura 4). 


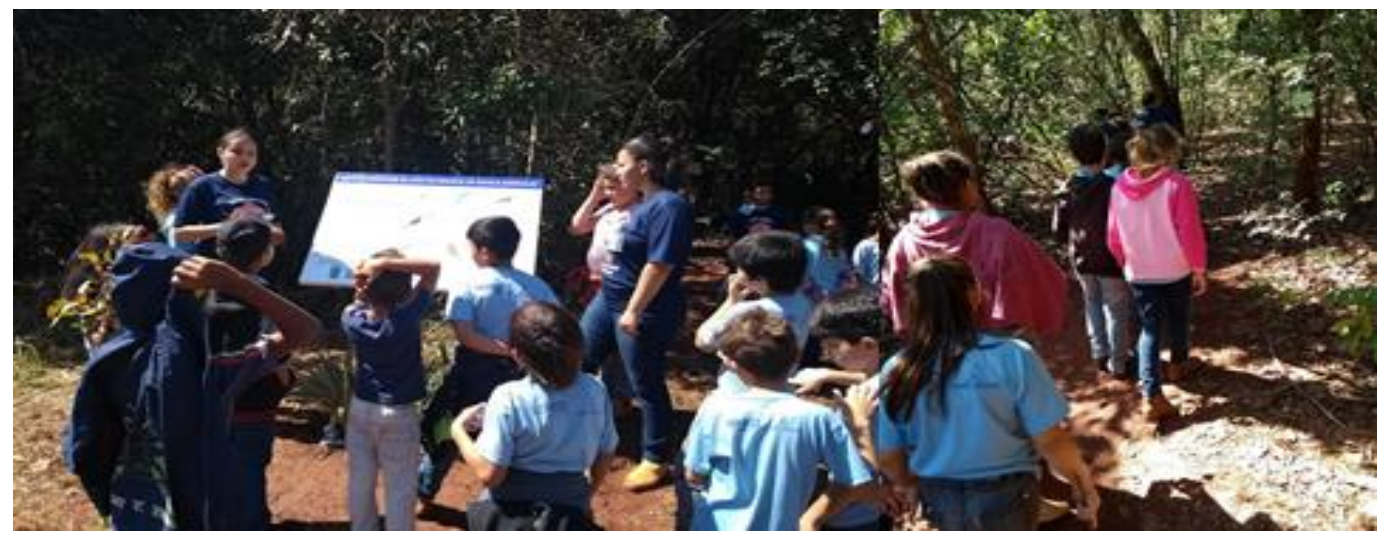

Figura 4: Visita monitorada dos alunos do $4^{\circ}$ ano do Ensino Fundamental Anos Iniciais da Escola Municipal Agrícola Gov. Arnaldo Estevão de Figueiredo.

Figure 4: Monitored visit of the students of the 4 th grade of Elementary School Early Years of the Agricultural Municipal School Gov. Arnaldo Estevão de Figueiredo.

Inicialmente a estratégia metodológica adotada seria apenas para os alunos da unidade escolar, porém Escolas públicas Municipais e Estaduais receberam informações sobre o trabalho desenvolvido na escola. Entraram em contato e visitas monitoradas formam organizadas.

5o Etapa: Durante o mês de novembro de 2018 duas escolas públicas, uma Municipal e outra Estadual participaram das atividades de campo, sendo 35 alunos do $8^{\circ}$ ano do Ensino Fundamental Anos finais e 51 alunos do $2^{\circ}$ e $3^{\circ}$ ano do Ensino Médio, totalizando 86 alunos (Figura 5).

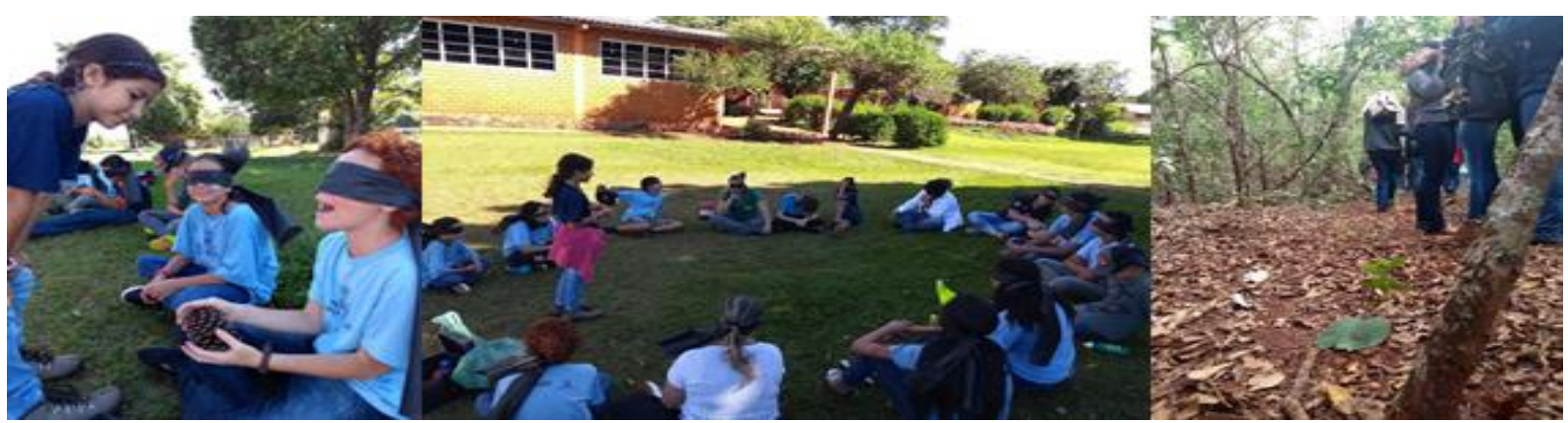

Figura 5: Atividade de Educação Ambiental e visita à trilha ecológica de uma Escola Pública de Campo Grande - MS.

Figure 5: Environmental Education Activity and visit to the ecological trail of a Public School of Campo Grande - MS

Foi possível nas atividades propostas abordar diversos assuntos como: Biodiversidade, Alterações ambientais, Ecologia, Educação Ambiental, Sustentabilidade, Cidadania, Turismo Ecológico, Uso e Ocupação do Solo, Desmatamento, Perda e Fragmentação de Habitats, Funções ecológica das Aves, Plantas do Cerrado, Educação Patrimonial.

Envolver áreas diferentes das biológicas contribuiu para o resultado satisfatório das atividades. O turismo pedagógico se destaca por fornecer diversas oportunidades de atividades de campo para o professor explorar, inovando ou diversificando os métodos de ensino, sendo seu roteiro de 
estudo, elaborado de acordo com o assunto trabalhado em sala, e em conjunto com as necessidades dos alunos e os objetivos que o professor pretende alcançar. Por meio desta prática é possível proporcionar aos alunos novos conhecimentos sobre diversas culturas, promovendo novas experiências que ampliam a visão cultural e aproximam do homem com 0 meio.

A utilização de passeios e viagens de estudo, pode não ser algo novo, mas permite uma experiência significativa e prazerosa no processo de ensino e aprendizagem. Freinet (2004) defende que o educador deve promover a ampliação dos olhares das crianças para fora do espaço escolar, onde o aluno é considerado o centro da construção de seu conhecimento e as relações sociais, econômicas e culturais interagem-se.

Para Gadotti (2000, p.133) "cidadania é, essencialmente, consciência de direitos e deveres". O cidadão pleno age como organizador da sociedade, atuando como protagonista da construção das novas relações de conhecimento e ressignificações de sua história de vida.

Para oferecer uma educação de qualidade as instituições de ensino devem acompanhar e renovar seus métodos de ensino. As práticas turísticas colaboram com o desenvolvimento e formação de cidadãos conscientes, é também uma oportunidade de trabalhar a interdisciplinaridade, que em conjunto com o planejamento e organização, possibilita maior interação entre diferentes professores e disciplinas.

Estimular a autonomia do aluno no processo de ensino aprendizagem, permite a discussão, reflexão e a formar alunos críticos. Faz parte da função da escola promover o diálogo sobre cidadania, responsabilidade social, ética, pluralidade. Oportunizando o desenvolvimento humano sobre três dimensões: a profissional; a pessoal e a social (FONSECA, 2014; ALARCÃO, 2001).

\section{Conclusões}

A escola como importante espaço de formação do sujeito, necessita continuamente buscar por novas alternativas pedagógicas para desenvolvimento do aluno. O Turismo como uma atividade de deslocamento serve como estratégia e suporte para os educadores diversificarem suas aulas, estas atividades não seguem um modelo definido ou uma atividade pronta. O roteiro deve ser montado de acordo com o assunto trabalhado em sala, em conjunto com as necessidades dos alunos e flexível a realidade de cada escola.

É o momento concreto do aluno interagir, perceber e se reconhecer como parte integrante no meio. Este recurso possibilita a junção da aprendizagem com o lazer, através de uma atividade que foge dos hábitos tradicionais de ensino e do cotidiano do aluno.

O aluno deve sentir-se desafiado, e sua curiosidade estimulada. Saber a realidade de seus alunos, suas deficiências e seus desafios diários em sala de aula, é o caminho mais promissor para o professor alcançar os 
objetivos desejados em suas aulas. Neste contexto o turismo pedagógico, amplia os limites de aprendizagem do aluno, proporcionando situações favoráveis à produção de conhecimentos, dentro de uma estrutura ampla de reflexão e a convivência entre pessoas de culturas diferentes.

O recomendável é que o turismo pedagógico seja inserido no projeto político pedagógico da escola, documento que norteia o trabalho pedagógico da unidade escolar. Construído de forma coletiva é a oportunidade de todos os membros da comunidade escolar contribuírem, definirem e organizarem as atividades e os projetos educativos necessários ao processo de ensino e aprendizagem. A escola é vista como um espaço de formação de cidadãos conscientes, responsáveis e críticos, que atuarão individual e coletivamente na sociedade, modificando os rumos que ela vai seguir. Favorece ao indivíduo sentimentos de conservação, manutenção e valorização dos bens patrimoniais, culturais e ambientais.

O Turismo Pedagógico enquanto pedagógica inovadora de aprendizagem, é capaz de contribuir para a Educação Ambiental. Essa forma de turismo proporciona um crescimento ao ser humano, constitui-se em uma atividade plena, no sentido que possibilita a educação patrimonial e a educação ambiental. A percepção do aluno se ressignifica e a partir das experiências sensoriais e cognitivas abre-se um novo canal de absorção do conhecimento.

\section{Referências Bibliográficas}

ALARCÃO, I. Escola reflexiva e nova racionalidade. Porto Alegre: Artmed, 2001.

APAP, G. (et al.). A Construção dos Saberes e da Cidadania: Da Escola à Cidade. Porto Alegre: Artmed, 2002.

ALZAN, N.C. Estudo do meio. In: CASTRO, A. D. et al. (org.). Didática para Escola de $1^{\circ}$ e $2^{\circ}$ Graus. 9. ed.. São Paulo: Pioneira, 1987.

BONFIM, M.V.S. Por uma pedagogia diferenciada: Uma reflexão acerca do turismo pedagógico como prática educativa. Revista Turismo Visão e Ação - Eletrônica, v. 12, no 1. p. 114 - 129, jan/abr. 2010.

CHIZZOTTI, A. Pesquisa qualitativa em ciências humanas e sociais. 2 . ed. Petrópolis: Vozes, 2008.

FETTER, S. A. Patrimônio Cultural: Raízes de uma Educação comprometida com o Desenvolvimento Regional. ANAIS...Territórios, Redes e Desenvolvimento Regional: Perspectivas e Desafios Santa Cruz do Sul, RS, Brasil, 2017. Disponível em: <https://online.unisc.br/acadnet/anais/ index.php/sidr/article/viewFile/16254/4262> Acesso: 19 fev. 2019.

FONSECA, Y. R. S. Turismo Pedagógico em Escola Pública: Uma Atividade ao uxílio da Educação. Trabalho de Conclusão de Curso. 2014. Universidade Federal Fluminense. Niterói. Disponível em: <https://app.uff.br/ riuff/bitstream/1/758/1/302\%20-\%20Yasmin\%20Fonseca.pdf>. Acesso: 12 fev. 2019. 
FREINET, C. A. Pedagogia do Bom Senso. 7. ed. São Paulo. Editora Martins Fontes, 2004.

GOMES, D. S.; MOTA, K. M. PERINOTTO, A. R. C. Turismo pedagógico como ferramenta de educação patrimonial: a visão dos professores de História em um colégio estadual de Parnaíba (Piauí, Brasil). Turismo \& Sociedade, Curitiba, v. 5, n.1, p. 82-103, abr. 2012. Disponível em: $<$ https://revistas.ufpr.br/turismo/article/viewFile/25326/17713>

GADOTTI, M. Pedagogia da terra. São Paulo: Petrópolis, 2000. Acesso: 19 fev. 2019.

LOUZEIRO, F.O.S. Experimentando o conhecimento: o Turismo Pedagógico como ferramenta para o Ensino Profissional. Revista Brasileira de Ecoturismo, São Paulo, n. 1 v.12, p.55-66, fev/abr, 2019.

MORIN, E. A cabeça bem-feita: repensar a reforma, reformar o pensamento. Tradução de Eloá Jacobina. 10 ed. Rio de Janeiro: Bertrand Brasil, 2004.

OLIVEIRA, D. S. Turismo Pedagógico como Instrumento do Processo Ensino Aprendizagem: O Caso da Escola Estadual Tristão de Barros Currais Novos/RN. Trabalho de Conclusão de Curso. 2016. CURRAIS NOVOS-RN. Disponível em <https://monografias.ufrn.br/jspui/bitstream/ 123456789/2214/1/Turismo\%20pedag\%C3\%B3gico\%20 Monografia.pdf>

Acesso: 13 fev.2019.

RUBIM, A. C. B. A prática do turismo pedagógico no contexto dos museus: a experiência de museus das cidades do Rio de Janeiro e Niterói. Niterói: UFF, 2010

SANTOS, C. M.; COLOMBO JÚNIOR, P. D. Interdisciplinaridade e Educação: Desafios e Possibilidades Frente à Produção do Conhecimento. Revista Triângulo, v.11, n.2, 2018.

GILLYS V. S.; ROSSARI, M, GIARETA, P. F. Projeto Político-Pedagógico Integrador: Uma Experiência da Rede Marista de Solidariedade na Educação Básica. Educere, XVIII Congresso Nacional de Educação. 2017, p.1970819717. Disponível em: <http://educere.bruc.com.br/arquivo/pdf2017/ 26430 13925.pdf > Acesso: 13 fev.2019.

VINHA, M. L. O turismo pedagógico e a possibilidade de ampliação de olhares. Hórus- Revista Eletrônica de Humanidades e Ciências Sociais Aplicadas. Ourinhos, SP, n. 3, 2005. Disponível em: <http://www.faeso.edu.br/horus >. Acessado em: 13 fev. 2019.

\section{Agradecimentos}

A Coordenação de Aperfeiçoamento de Pessoal de Nível Superior (Capes) pela Bolsa de Pesquisa.

Ao Instituto Arara Azul pelo apoio financeiro nas ações de Educação Ambiental.

Ao Instituto Mamede pela ajuda técnica nas Passarinhadas. 
Rosiane de Morais: Universidade Anhanguera Uniderp, Campo Grande, MS, Brasil.

E-mail: morais.rosiane@gmail.com

Link para o currículo Lattes: http://lattes.cnpq.br/3326612002858051

Luciana Paes de Andrade: Universidade Anhanguera Uniderp, Campo Grande, MS, Brasil.

E-mail: luciana.andrade@uniderp.com.br

Link para o currículo Lattes: http://lattes.cnpq.br/7517005402820380

Neiva Maria Robaldo Guedes: Universidade Anhanguera Uniderp, Campo Grande, MS, Brasil.

E-mail: guedesneiva@gmail.com

Link para o currículo Lattes: http://lattes.cnpq.br/7358580565148346

Data de submissão: 26 de fevereiro de 2019

Data de recebimento de correções: 14 de abril de 2019

Data do aceite: 14 de abril de 2019

Avaliado anonimamente 